\title{
Single-operator cholangioscopy for the diagnosis of bile duct lymphoma: a case report and brief review of the literature
}

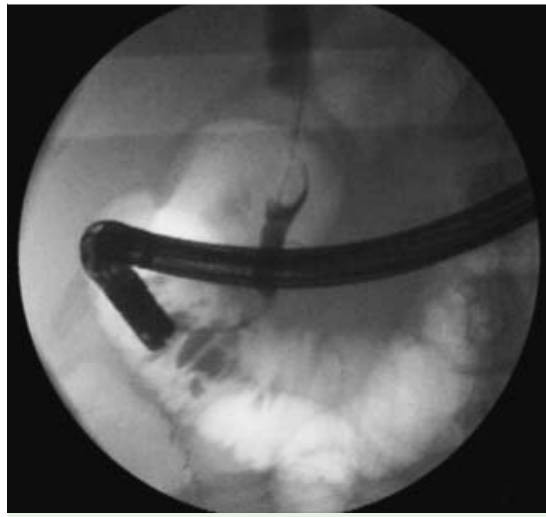

Fig. 1 Cholangiogram evidenced a round filling defect in the distal bile duct; scope in the long position.

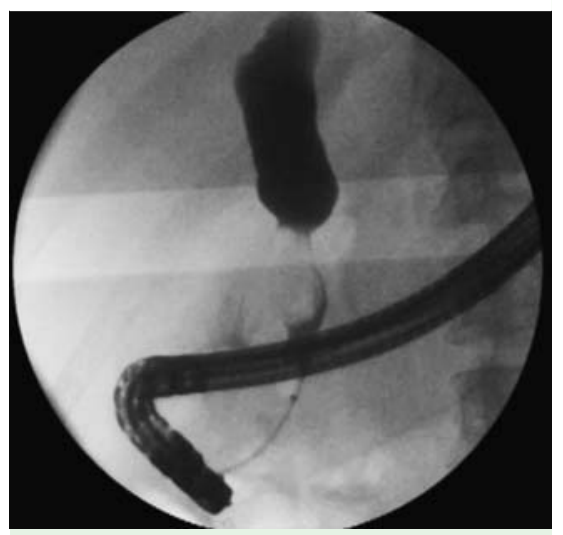

Fig. 2 Occlusion cholangiogram showed a mass in the lower part of the bile duct associated with bile duct stricture and proximal biliary duct dilatation.

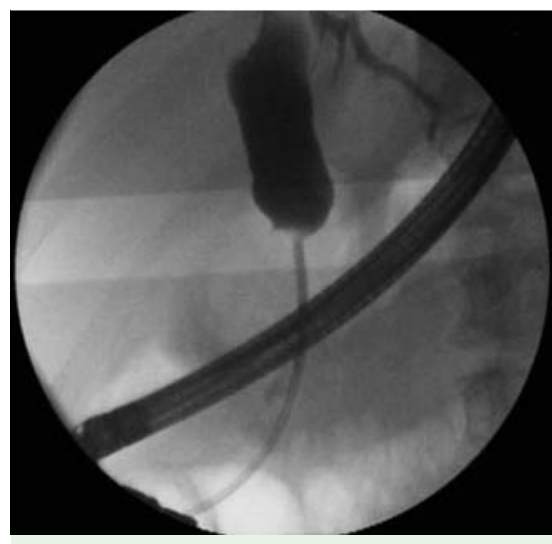

Fig. 3 Single-operator cholangioscopy catheter advanced through the stricture into the proximal bile duct.

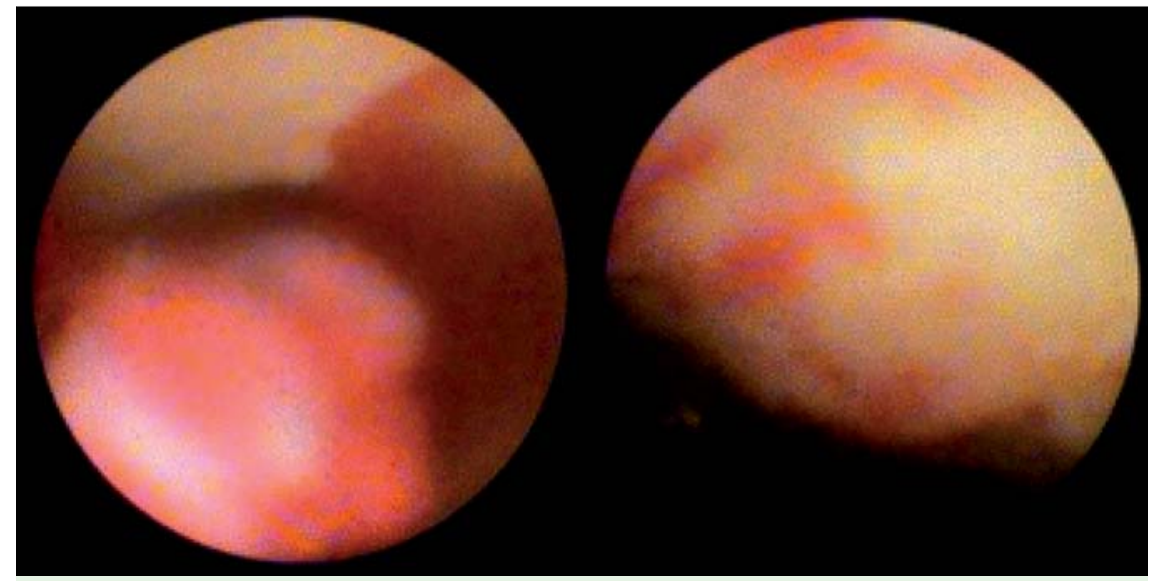

Fig. 4 Single-operator cholangioscopy: a large nodule occupying the lumen of the bile duct; $\mathbf{b}$ increased vascularity and ulcer associated with the mass in the bile duct.

Locally advanced mucosa-associated lymphoid tissue (MALT) causing obstructive jaundice due to involvement of the common bile duct (CBD) is a particularly rare condition. In the literature there are only 24 case reports of primary CBD lymphoma. To our knowledge there are no case reports of recurrent locally advanced MALT presenting as biliary obstruction and diagnosed with single-operator cholangioscopy.

A 67-year-old man with a medical history of Crohn's disease, duodenal MALT treated with chemotherapy, and prostate and bladder cancers, was admitted to the hospital with new-onset jaundice. Liver tests showed a total bilirubin concentration of $25.6 \mu \mathrm{mol} / \mathrm{L}$, direct bilirubin $20.5 \mu \mathrm{mol} / \mathrm{L}$, alkaline phosphatase $414 \mathrm{U} / \mathrm{L}$, aspartate aminotransferase $103 \mathrm{U} / \mathrm{L}$, and alanine aminotransferase 9U/L. Magnetic resonance imaging of the abdomen showed moderate to severe intra- and extrahepatic biliary dilation and an obstructing mass at the level of the mid to distal CBD. The mass appeared to be encasing the CBD. Endoscopic retrograde cholangiopancreatography (ERCP) was performed. The cholangiogram revealed a mid-CBD stricture with a round filling defect causing obstruction and proximal biliary dilatation ( $\bullet$ Fig. 1 and $\odot$ Fig. 2 ). For better assessment of the stricture and the filling defect, a SpyGlass probe (Boston Scientific, Natick, Massachusetts, USA) was introduced ( $\bullet$ Fig.3), revealing a round, nodu- lar mass in the middle of the bile duct, with associated luminal reduction, ulceration, and increased vascularity ( $\bullet$ Fig. 4 , - Video 1). Biopsies were obtained (SpyBite; Boston Scientific) and a fully covered metal biliary stent was placed with excellent drainage. Histopathology revealed lymphoid proliferation infiltrating the mucosa with immunohistochemistry stains compatible with MALT ( $\bullet$ Fig.5). The biliary obstruction with secondary jaundice resolved after the placement of the metal stent and the patient is currently receiving chemoradiation.

Lymphoma involving the bile duct is rare and is commonly a manifestation of advanced disease [1]. Biliary obstruction caused by lymphoma occurs in only $1 \%$ $2 \%$ of all malignant strictures [2]. Obstructive jaundice, weight loss, abdominal pain, and fever are the most common symptoms upon presentation [3]. At the time of diagnosis, low-grade MALT lymphomas usually are localized and curable with local therapy [4]. Lymphoma involving the

\section{Video 1}

Cholangioscopy revealed a round, friable, nodular mass with increased vascularity. Because of persistent oozing, continuous irrigation was necessary to enable visualization of the lesion. The mass with associated exophytic component could be visualized laterally to the normalappearing bile duct. Multiple direct cholangioscopy biopsies were taken. 

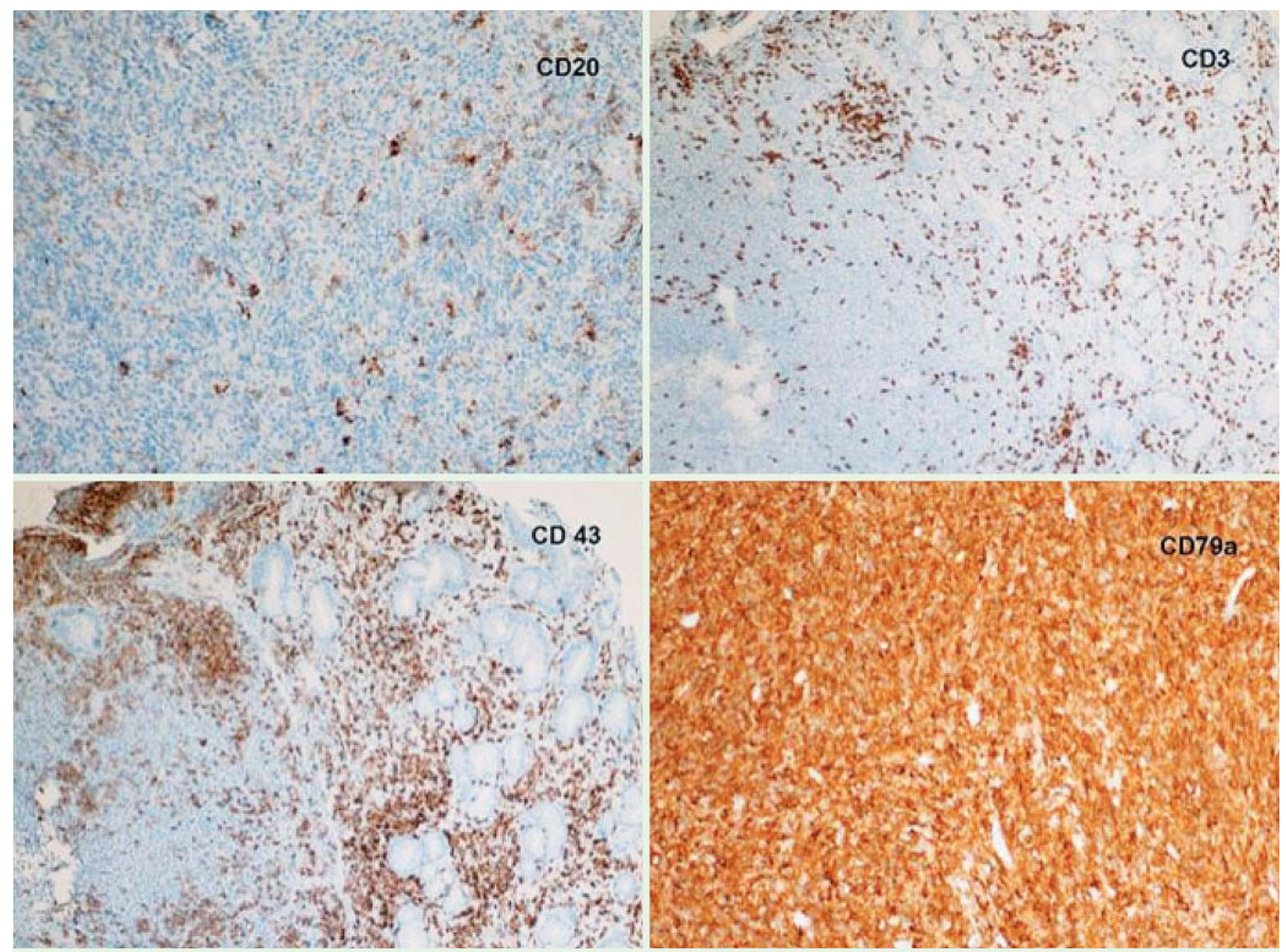

Fig.5 Immunohistochemistry stains from single-operator cholangioscopic biopsies consistent with B-cell lymphoma.

bile duct is very difficult to diagnose preoperatively [5]. As exemplified by our case, single-operator cholangioscopy can be used to diagnose biliary lymphoma at the time of therapeutic ERCP.

Endoscopy_UCTN_Code_CCL_1AZ_2AC

\section{Competing interests: None}

\section{Torrealba', M. Berzosa², I. Raijman ${ }^{3}$}

' CIMA Hospital, Medicine San Jose, Costa Rica

2 Baylor College of Medicine, Gastroenterology and Hepatology, Houston, Texas, United States

3 Digestive Associates of Houston, Gastroenterology, Houston, Texas, United States

\section{References}

1 Yoon MA, Lee JM, Kim SH et al. Primary biliary lymphoma mimicking cholangiocarcinoma: a characteristic feature of discrepant $\mathrm{CT}$ and direct cholangiography findings. J Korean Med Sci 2009; 24: 956-959

2 Joo YE, Park CH, Lee WS et al. Primary nonHodgkin's lymphoma of the common bile duct presenting as obstructive jaundice. J Gastroenterol 2004; 39: 692-696

3 Luigiano C, Ferrara F, Fabbri C et al. Primary lymphoma of the common bile duct presenting with acute pancreatitis and cholangitis. Endoscopy 2010; 42: E265-E266

4 Kang CS, Lee YS, Kim SM et al. Primary low grade B cell lymphoma of mucosa associated lymphoid tissue type of the common bile duct. J Gastroenterol Hepatol 2001; 16: 949-951

5 Dote $H$, Ohta $K$, Nishimura $R$ et al. Primary extra nodal non-Hodgkin's lymphoma of the common bile duct manifesting as obstructive jaundice: report of a case. Surg Today 2009; 39: 448 - 451

\section{Bibliography}

Dol http://dx.doi.org/

10.1055/s-0033-1344593

Endoscopy 2013; 45: E359-E360

(c) Georg Thieme Verlag KG

Stuttgart · New York

ISSN 0013-726X

\section{Corresponding author}

\section{Raijman, MD}

Baylor Clinic Building

6620 Main Street

Suite 1510

Houston, TX 77030

USA

Fax: +1-713-7955254

raijman.i@gmail.com 